to remedy a capital inconvenience, I have contrived that my patients (at Vernet) should be subjected to the very atmosphere of sulphurous waters, in a place built specially for the purpose, in which the vapour, entering from below, escapes from above; this constant current also maintaining a temperature of about eighteen or twenty degrees centigrade, which may, however, be varied at pleasure, as well as the quantity of vapour in circulation.

According to my plan, the patients at first remain in it one hour, morning and evening; they soon accustom themselves to remain in it twelve hours a day without feeling inconvenience, and are able to employ themselves in their usual occupations.

I have at this moment several consumptive patients, who have been entirely cured within the space of two or three years, and who return hither to pass the worst days of the winter, from the fear of a relapse. Many of them, indeed, have quitted Pisa or Naples, in order to return and plunge themselves into vapours which had been of such great use to them, and the place of which cannot be supplied by the most beautiful climate in the world. I beg it to be particularly remarked, that I have treated here pulmonary cases, in which the existence of tubercles has been fully ascertained by the stethoscope - pulmonary diseases, accompanied by nightsweats-by colliquative diarrhœas-in short, all the symptoms which accompany the last period of this cruel malady, whose name alone is considered to be a death-warrant."

April, 1846.

\section{PREVENTION OF ILLEGAL PRACTICE BY REGISTRATION.}

To the Editor of THE Lancet.

SrR,-Having several times, of late, observed in your periodical, remarks as to the utility of the register of deaths in preventing the practice of unqualified men, allow me to state, that if any good is to be derived from this quarter, it must be through the exertions of medical men, and particularly of the Apothecaries' Company. If medical men made one invariable rule of giving certificates to the friends of deceased persons, for the purpose of registration, such certificates would be prima facie evidence of their being qualified; or if unqualified persons gave such certificates, they would give the best proof of their having attended a patient; and with a little additional assistance from the registrar, the Apothecaries' Company might generally obtain sufficient evidence of their having made a charge for so doing, which $\mathrm{I}$ believe is all that is necessary to ensure a conviction.

Still our difficulty remains : who is to inform the Apothecaries' Company? If it is not made a part of the duty of the registrar, he will have the same delicacy on this point as medical men generally. The only plan of overcoming this appears to me to be, that the registrar-general should require every registrar to send him the name of any unqualified person whose certificate he might receive, and which he might forward to the Apothecaries' Company.

In order to carry out this plan efficiently, of course it would be necessary that every registrar of deaths should be furnished, by the Apothecaries' Company, with a correct list of its licentiates.-I am, Sir, your most obedient servant,

Camden Town, May, 1846 . JOSEPH CURTIS.

DEATH FROM IMPACTION OF A FRAGMENT OF FOOD WITHIN THE ARYTENOID CARTILAGES,

\section{To the Editor of The Lancet.}

SIR,-I agree with Dr. Letheby on the great importance of minute examinations in all cases of suspicious sudden death, not only for the sake of justice, but, as the following case will show, for the sake of the suspected.

On the 22nd of March I was summoned to see a child: on arriving, it was dead. Externally, there was nothing seen to account for death. From the circumstance of two children of the parents having died previously at short intervals, in a similar and sudden manner, I considered it my duty to desire an inquest.

I opened the body, by direction of the coroner, (Mr. Wak ley,) fifty-two hours after death, and examined all the organs, and the contents of the stomach chemically; but nothing was found to account for death,-nothing, indeed, remarkable, except the very ancemic condition throughout; in the brain, the cineritious and medullary portions were scarcely to be distinguished by colour.

Hearing it incidentally mentioned by the person in attendance that the mother's milk had been scanty, that the infant had been commonly fed on boiled French roll, and that a cough had suddenly come on the Wednesday preceding, (the 22nd, the day of its death,) after its usual food, I thought I saw a clne to the mystery, and immediately opened the trachea in its whole extent.

Within the arytenoid cartilages there was a substance of a brown hue, enveloped by mucus, and below this substance, a quantity of thickened mucus. I compared the substance with the contents of the stomach, and found many identical substances. Mr. Girdwood was of the same opinion. I have rio doubt, that on the Wednesday the substance had passed into the air-passages, causing the cough, and that, on the Sunday morning, from a change of position, it produced asphyxia.

It was very satisfactory to me to be able to assign a cause of death before the coroner, (a surgeon, as all coroners should be;) and it must have been very gratifying to the parents, on whom suspicion had rested in the minds of neighbours, who very maturally thought it strange that their three children had died under apparently similar circumstances within a short time.-I am, Sir, your very obedient servant,

Southwick-crescent, April, 1846.

J. M. Mustarde.

\section{PRIVATE LUNATIC ASYLUMS.}

To the Editor of THE LanceT.

Srr, - I venture to hope that the importance of the subject will be a sufficient apology for my troubling you with this communication.

In an unlicensed house in the outskirts of this city, an insane lady of rank was lately confined, in direct violation of the law; and in the same house, in the month of December last, under the very walls of a lunatic asylum, another patient, under similar circumstances, lost her life, having been allowed to go seven clear days without food.

Lincoln, April, 1846. I am, Sir, your obedient servant, JUSTrist.

"Dr. Turner and Mr. Proctor attended Lincoln, on Friday last, as a special commission from her Majesty's Board of Lunacy Commissioners, to inquire into the circumstances of a person's being confined in an unlicensed house, contrary to the new law. Having called upon Mr. Graham, surgeon of the Asylum, the Commissioners proceeded to the house of a person named Houseley, near the Asylum, and found that the lunatic had been removed to Boulogne, in the custody of Houseley's wife. Evidence was afterwards taken at the Saracen's Head with regard to the affair, and Houseley was examined as to whose direction he had been acting under; and we are informed that his statement implicates a gentleman of the city who could not be ignorant of the law. We also are informed that the Commissioners were acquainted with the facts of a case where a female was similarly confined some short time since, who got under the delusion that it would displease the Almighty if she took food, (a not unfrequent delusion in cases of insanity, and who for seven days prior to the last two or three days of her life, was allowed to go without food being administered, by which prostration was produced, and she died in consequence. This fact alone, taking it as one, establishes the propriety of the new law abolishing private confinement; for had the female bocn under the care of the officers of a regular establishment, she would not have been allowed to fast longer than a day at most. In this case, we are informed, a special commission of inquiry is to be issued. Having taken evidence in the first case to frame a report to the board, the Commissioners proceeded to the south of Lincolnshire, to examine a second case. These matters show the necessity of the watchful care of a public board like the one called into existence; for, as an illustrious writer observes, "secrecy is the parent and guardian of abuse; publicity its irresistible enemy." -Stamford Mercury, A pril 21.

The correspondent who has forwarded us the above statement, assures us, that Mr. Proctor, the Commissioner in Lunacy, was heard to say-"If Mr. Wakley had been coroner for Lincoln instead of for Middlesex, your name, (meaning the owner of the unlicensed house, and the medical attendants of the dead woman, wonld now have been notorious in every corner of England."

NEWS, REMARKS, AND CRITICISMS.

The Vestiges of Creation, and Progressive Development. Extract from a letter of a Correspondent."Your readers are doubtless well acquainted with this profound work, and will remepber the experiments of $\mathbf{M r}$. Weekes, of Sandwich, who has succeeded in 'developing' 'insect life,' by means of Daniel's constant battery, applied 